\title{
Article \\ Effect of Ion-Exchange Sequences on Catalytic Performance of Cerium-Modified Cu-SSZ-13 Catalysts for $\mathrm{NH}_{3}-\mathrm{SCR}$
}

\author{
Yan Wang ${ }^{1,2}$, Zhaoqiang Li ${ }^{1,2, * \mathbb{D}}$, Zhiyong Ding ${ }^{1,2}$, Na Kang ${ }^{1,2}$, Rongrong Fan ${ }^{1,2}$, Yu Wang ${ }^{1,2}$, Cheng Zhang ${ }^{1,2}$ \\ Xin Guo ${ }^{1,2}$ and Rong Wang ${ }^{1,2}$ \\ 1 State Key Laboratory of Baiyunobo Rare Earth Resource Researches and Comprehensive Utilization, \\ Baotou Research Institute of Rare Earths, Baotou 014030, China; wangyan@brire.com (Y.W.); \\ dingzhiyong@brire.com (Z.D.); kangna@brire.com (N.K.); fanrongrong@brire.com (R.F.); \\ wangyu2021@brire.com (Y.W.); zhangcheng2021@brire.com (C.Z.); guoxin@brire.com (X.G.); \\ wangrong@brire.com (R.W.) \\ 2 National Engineering Research Center of Rare Earth Metallurgy and Functional Materials, \\ Baotou 014030, China \\ * Correspondence: lizq@brire.com; Tel.: +86-151-4939-4414
}

check for updates

Citation: Wang, Y.; Li, Z.; Ding, Z.; Kang, N.; Fan, R.; Wang, Y.; Zhang, C.; Guo, X.; Wang, R. Effect of

Ion-Exchange Sequences on Catalytic Performance of Cerium-Modified Cu-SSZ-13 Catalysts for $\mathrm{NH}_{3}$-SCR. Catalysts 2021, 11, 997.

https://doi.org/10.3390/

catal11080997

Academic Editor: Anker Degn Jensen

Received: 17 June 2021

Accepted: 16 August 2021

Published: 19 August 2021

Publisher's Note: MDPI stays neutral with regard to jurisdictional claims in published maps and institutional affiliations.

Copyright: (c) 2021 by the authors. Licensee MDPI, Basel, Switzerland. This article is an open access article distributed under the terms and conditions of the Creative Commons Attribution (CC BY) license (https:/ / creativecommons.org/licenses/by/ $4.0 /)$.

\begin{abstract}
Cerium-modified Cu-SSZ-13 catalysts were prepared by an aqueous ion-exchange method, and $\mathrm{Ce}$ and $\mathrm{Cu}$ were incorporated through different ion-exchange sequences. The results of $\mathrm{NH}_{3}-\mathrm{SCR}$ activity evaluations displayed that $\mathrm{Cu} 1(\mathrm{CeCu}) 2$ catalyst presented excellent catalytic activity, and over $90 \% \mathrm{NO}_{x}$ conversion was obtained across the temperature range of $200-500{ }^{\circ} \mathrm{C}$. The characterization results showed that the ion-exchange sequence of $\mathrm{Cu}$ and $\mathrm{Ce}$ species influenced the crystallinity of the zeolites and the coordination of Al. A small amount of Ce could participate in the reduction process and change the location and coordination environment of copper ions. Furthermore, Ce-modified Cu-SSZ-13 catalysts possessed more acidic sites due to their containing replacement of Ce and movement of $\mathrm{Cu}$ in the preparation process. The cooperation of strong redox abilities and $\mathrm{NH}_{3}$ storage capacity led to the increase of active adsorbed species adsorption and resulted in better activity of $\mathrm{Cu} 1(\mathrm{CeCu}) 2$.
\end{abstract}

Keywords: cerium; Cu-SSZ-13; ion-exchange sequences; SCR; drifts

\section{Introduction}

With the rapid development of the economy, environmental issues-especially nitrogen oxides $\left(\mathrm{NO}_{x}\right)$ emitted from diesel vehicles-are getting growing attention. There is evidence that states that diesel vehicles accounted for about $10 \%$ of automobiles producing nearly $90 \%$ of $\mathrm{NO}_{x}$ emitted from automobiles in China. To achieve ultra-low exhaust emission levels, China will implement the China VI Standards to control $\mathrm{NO}_{x}$ pollutants emitted from diesel-fueled, heavy-duty vehicles. In exhaust aftertreatment system of diesel vehicles, the selective catalytic reduction of $\mathrm{NO}_{x}$ with $\mathrm{NH}_{3}\left(\mathrm{NH}_{3}-\mathrm{SCR}\right)$ has high efficiency and is currently considered as the most preeminent technology for $\mathrm{NO}_{x}$ removal. Among all catalysts, $\mathrm{Cu}-\mathrm{SSZ}-13$ with small-pore structure has been proven to be the most promising catalyst in the $\mathrm{NH}_{3}-\mathrm{SCR}$ reaction [1-4].

As we know, the complicated and changeable cold-start and low-load conditions of diesel vehicles make it more challenging for Cu-SSZ-13 catalyst in a wide variety of temperatures $\left(200-600{ }^{\circ} \mathrm{C}\right)$. Also, Cu-SSZ-13 catalyst must have excellent hydrothermal stability, because the SCR unit is located in the high-temperature environment, due to the regeneration of the upstream diesel particle filter (DPF) (above $650{ }^{\circ} \mathrm{C}$ ) [1]. Recently, several rare earth modified $\mathrm{Cu}-\mathrm{SSZ}-13$ catalysts have been widely reported resulting from their easy operability, outstanding de- $\mathrm{NO}_{x}$ efficiency, and high improvement on hydrothermal stability. Usui et al. [5] demonstrated that introduction of a small amount of Ce by wet and solid-state ion-exchange routes could improve SCR activities over a broad temperature 
range, because it enabled abundant Brønsted acidity sites and stabilized the framework of SSZ-13. The results of Zhao et al. [6] also confirmed that rare earth ions $\left(\mathrm{Ce}^{3+}, \mathrm{La}^{3+}\right.$, $\mathrm{Sm}^{3+}, \mathrm{Y}^{3+}, \mathrm{Yb}^{3+}$ ) that modified Al-rich Cu-SSZ-13 catalysts had no significant impact on low-temperature $\mathrm{NO}$ conversions in the fresh catalyst but displayed enhancement of low temperature activity after hydrothermal aging when compared with Cu-SSZ-13. Similarly, Wang et al. [7] reported that $\mathrm{Ce}$ or Sm could be introduced into Cu-SSZ-13 by ion exchanged preparation procedures, and the counterparts were investigated in detail. They found that the coexistence of $\mathrm{Ce}$ or Sm could exhibit higher hydrothermal stability due to its preventing the framework $\mathrm{Al}$ from hydrolysis. Nevertheless, only few research works focused on using different ion-exchange sequences of rare earth and copper ions to modify SSZ-13 zeolite and investigating its $\mathrm{NH}_{3}-\mathrm{SCR}$ performance.

In this study, we prepared Ce-modified Cu-SSZ-13 catalysts by an aqueous ionexchange method and investigated the effect of different ion-exchange sequences of $\mathrm{Cu}$ and Ce on the SCR activity and hydrothermal stability of catalysts. XRD, $\mathrm{N}_{2}$ adsorptiondesorption, as well as ${ }^{29} \mathrm{Si}$ and ${ }^{27} \mathrm{Al} \mathrm{NMR}$ were carried out to investigate the textural and structural properties of the Ce-modified Cu-SSZ-13 catalysts. Besides, $\mathrm{H}_{2}-\mathrm{TPR}$ and $\mathrm{NH}_{3}$-TPD were used to explore the variation of reduction property and surface acidity.

\section{Results and Discussion}

\subsection{Catalytic Performance}

Figure 1 depicted the $\mathrm{NH}_{3}-\mathrm{SCR}$ performance of $\mathrm{Cu}-\mathrm{SSZ}-13$ and Ce-modified $\mathrm{Cu}-$ SSZ-13 catalysts with the temperature change. As shown in Figure 1a, it can be seen that $\mathrm{Cu}$-SSZ-13 displayed high $\mathrm{NO}_{x}$ conversions $(>90 \%)$ in the temperature range of $200-400{ }^{\circ} \mathrm{C}$. Note that $\mathrm{Cu} 1(\mathrm{CeCu}) 2,(\mathrm{CeCu}) 12$ and $(\mathrm{CeCu}) 1 \mathrm{Cu} 2$ displayed an enhancement in activity compared with Cu-SSZ-13 at low and high temperatures. In the case of the $(\mathrm{CeCu}) 1 \mathrm{Cu} 2$ sample, it showed the highest catalytic performance at $200{ }^{\circ} \mathrm{C}$ and nearly $100 \% \mathrm{NO}_{x}$ conversion was obtained at this temperature. As compared with $\mathrm{Cu}-\mathrm{SSZ}-13$, however, the $\mathrm{NO}_{x}$ conversion of $(\mathrm{CeCu}) 1 \mathrm{Cu} 2$ decreased from 71 to $64 \%$ at $550{ }^{\circ} \mathrm{C}$ and 59 to $52 \%$ at $600{ }^{\circ} \mathrm{C}$. For $(\mathrm{CeCu}) 12$ and $\mathrm{Cu} 1(\mathrm{CeCu}) 2$, the low-temperature SCR activity $\left(200{ }^{\circ} \mathrm{C}\right)$ and high-temperature activity $\left(>400{ }^{\circ} \mathrm{C}\right)$ were enhanced significantly compared to the $\mathrm{NO}_{x}$ conversions obtained with the $\mathrm{Cu}-\mathrm{SSZ}-13$ catalyst. Figure $1 \mathrm{~b}$ revealed the SCR activity of these four catalysts after hydrothermal aging with $10 \% \mathrm{H}_{2} \mathrm{O}$ at $850{ }^{\circ} \mathrm{C}$ for $10 \mathrm{~h}$ under the GHSV of $60,000 \mathrm{~h}^{-1}$. It can be seen that the $\mathrm{NO}_{x}$ conversion of all catalysts decreased to different degrees, but the activity of $\mathrm{Cu} 1(\mathrm{CeCu}) 2$ and $(\mathrm{CeCu}) 1 \mathrm{Cu} 2$ was obviously higher than that of Cu-SSZ-13 at high temperature $\left(450-600{ }^{\circ} \mathrm{C}\right)$. Therefore, it was clear that introduction of Ce ions in Cu-SSZ-13 had significant impact on the activity, and $\mathrm{Cu} 1(\mathrm{CeCu}) 2$ was selected as the optimum catalyst due to its excellent $\mathrm{NH}_{3}$-SCR performance, and over $90 \% \mathrm{NO}_{x}$ conversion of fresh catalyst was obtained across the temperature range of $200-500{ }^{\circ} \mathrm{C}$.

\subsection{Textural Properties}

The XRD patterns of Cu-SSZ-13 and Ce-modified Cu-SSZ-13 catalysts were shown in Figure 2. It could be seen that all catalysts exhibited a typical chabazite (CHA) crystal structure with characteristic $2 \theta$ degrees at $9.6^{\circ}, 13.0^{\circ}, 16.1^{\circ}, 18.1^{\circ}, 20.7^{\circ}, 25.2^{\circ}, 26.3^{\circ}$ and $31.0^{\circ}$ (PDF data file 52-0784) [8,9]. No noticeable diffraction peaks assigned to $\mathrm{Cu}$ species and Ce species were observed indicating that those should be present in the form of isolated ions or highly dispersed on the zeolite crystals [10-12]. There was no obvious difference in diffraction peak position between the catalysts, suggesting the introduced Ce species did not change the CHA structure. The peak intensity had been reported to correlate with the crystallinity of the zeolites [13,14]. As the pattern shown, the intensity of the characteristic peaks of $\mathrm{Cu}-\mathrm{SSZ}-13$ and $\mathrm{Cu} 1(\mathrm{CeCu}) 2$ at $9.6^{\circ}$ was much higher than that of $(\mathrm{CeCu}) 12$ and $(\mathrm{CeCu}) 1 \mathrm{Cu} 2$ samples, an effect that might be related to the ion-exchange sequence of the cerium species. As reported by Usui [5], the cerium species in the Cu-SSZ-13 should be present in the form of isolated ions as long as the cerium loading was less than $3 \mathrm{wt} . \%$, 
and over $3 \mathrm{wt} . \%$ cerium species located at extra ion-exchange sites should not affect the crystallographic features of the zeolite catalyst. This was associated with our observation (Figure 2 and Table 1) and also illustrated that Ce cations in $\mathrm{Cu} 1(\mathrm{CeCu}) 2,(\mathrm{CeCu}) 12$, and $(\mathrm{CeCu}) 1 \mathrm{Cu} 2$ were located at the ion-exchange sites in double six-ring (D6R) or CHA cage.

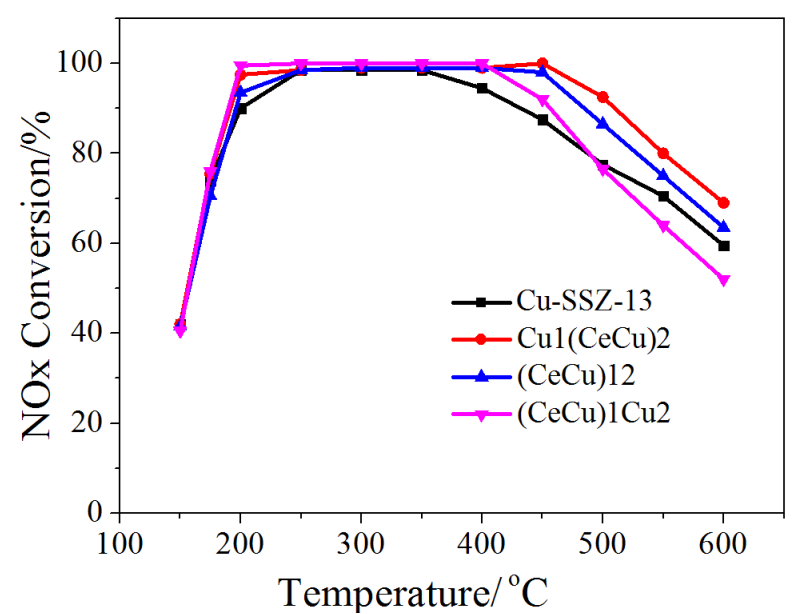

(a)

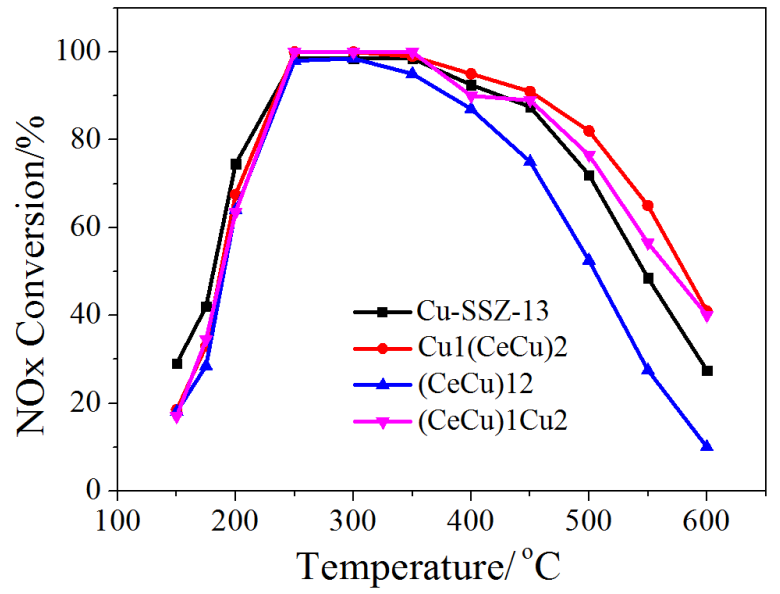

(b)

Figure 1. $\mathrm{NH}_{3}$-SCR performance of fresh (a) and aged (b) Cu-SSZ-13 and Ce-modified Cu-SSZ-13 catalysts.

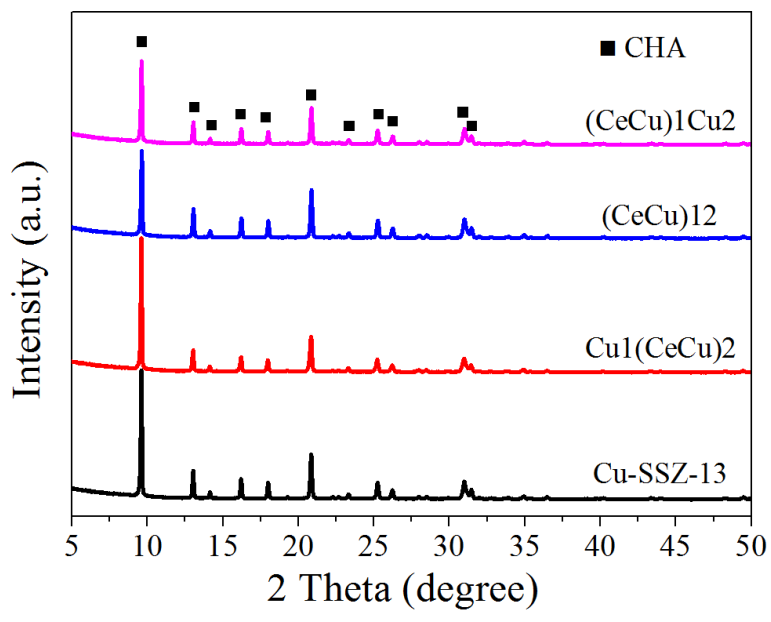

Figure 2. XRD profiles of Cu-SSZ-13 and Ce-modified Cu-SSZ-13 catalysts.

Table 1. Elemental compositions and textural properties over Cu-SSZ-13 and Ce-modified Cu-SSZ-13 catalysts.

\begin{tabular}{ccccc}
\hline Samples & $\mathbf{C u O ~ ( \% )}{ }^{\mathbf{a}}$ & $\mathbf{C e O}_{\mathbf{2}}(\mathbf{p p m})^{\mathbf{a}}$ & $\begin{array}{c}\text { Langmuir Surface Area } \\
\left(\mathbf{m}^{\mathbf{2}} / \mathbf{g}\right)\end{array}$ & $\boldsymbol{V}_{\mathbf{T}}(\mathbf{m L} / \mathbf{g})^{\mathbf{b}}$ \\
\hline $\mathrm{Cu}-\mathrm{SSZ}-13$ & 1.90 & - & 793.7 & 0.2789 \\
$\mathrm{Cu}(\mathrm{CeCu}) 2$ & 1.83 & 120 & 763.3 & 0.2695 \\
$(\mathrm{CeCu}) 12$ & 2.04 & 130 & 768.6 & 0.2730 \\
$(\mathrm{CeCu}) 1 \mathrm{Cu} 2$ & 1.84 & 60 & 803.1 & 0.2779 \\
\hline
\end{tabular}

${ }^{\mathrm{a}}$ Calculated by ICP. ${ }^{\mathrm{b}} V_{\mathrm{T}}$ is the t-Plot micropore volume.

Figure 3 presented $\mathrm{N}_{2}$ adsorption-desorption isotherms and pore width distribution curves over Cu-SSZ-13 and Ce-modified Cu-SSZ-13 catalysts. All samples showed typical type I isotherms according to the BDDT classification, which was consistent with the microporous materials $[15,16]$. Although the DFT model pore size distribution showed that $\mathrm{Cu}-\mathrm{SSZ}-13, \mathrm{Cu} 1(\mathrm{CeCu}) 2,(\mathrm{CeCu}) 12$, and $(\mathrm{CeCu}) 1 \mathrm{Cu} 2$ catalysts had only a narrow visible 
peak at around $0.73 \mathrm{~nm}$, there was still a little difference in pore size after loading of Ce. The surface area and the t-Plot micropore volume of the prepared catalysts were listed in Table 1 . The results showed that all samples had Langmuir surface area over $760 \mathrm{~m}^{2} / \mathrm{g}$ and total pore volume over $0.26 \mathrm{~mL} / \mathrm{g}$.

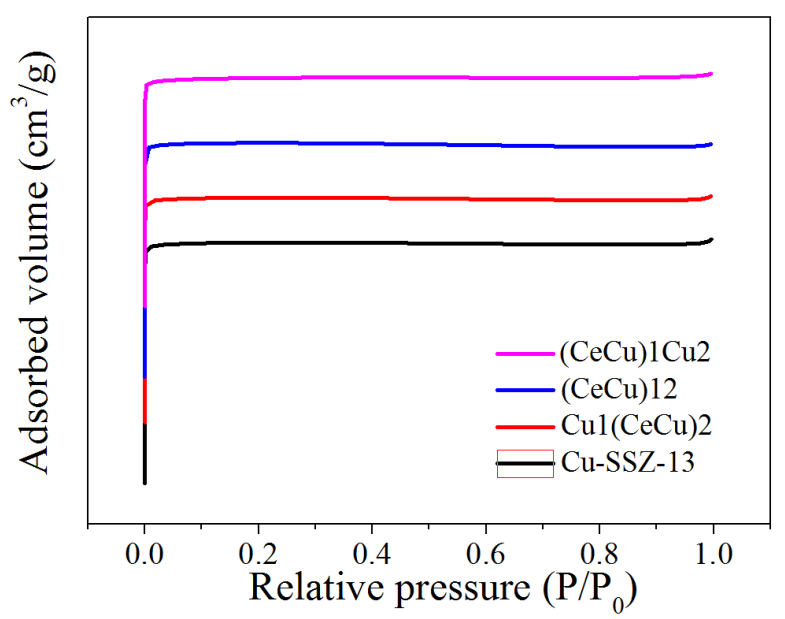

(a)

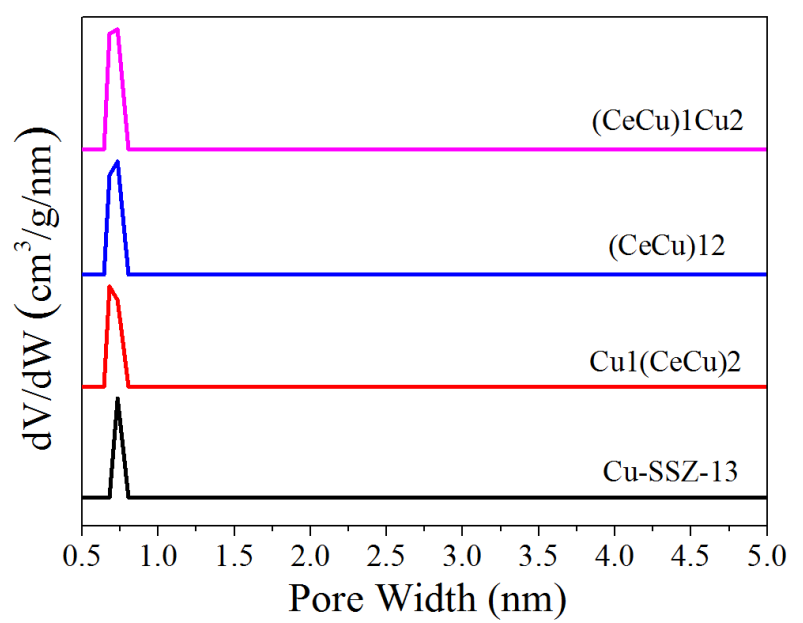

(b)

Figure 3. $\mathrm{N}_{2}$ adsorption-desorption isotherms (a) and pore width distribution curves (b) of the catalysts.

\subsection{NMR Measurements}

As displayed in Figure 4, solid state NMR measurements were used to monitor the effects of ion-exchange sequence of $\mathrm{Cu}$ and $\mathrm{Ce}$ species on $\mathrm{Al}$ and $\mathrm{Si}$ atoms in the framework of SSZ-13. From ${ }^{27} \mathrm{Al}$ NMR spectra (Figure 4a), one resonance feature at a chemical shift of $54 \mathrm{ppm}$ in all these samples was corresponded to tetrahedral $\mathrm{Al}$ in the zeolite framework. Meanwhile, a small amount of extra-framework octahedral $\mathrm{Al}$ atoms near 5 ppm was observed in the curves of all the catalysts. Apparently, the intensity of the panels over $\mathrm{Cu} 1(\mathrm{CeCu}) 2,(\mathrm{CeCu}) 12$, and $(\mathrm{CeCu}) 1 \mathrm{Cu} 2$ catalysts decreased significantly compared to $\mathrm{Cu}$ SSZ-13, signifying that the introduction of Ce had a great effect on the coordination of $\mathrm{Al}$ in molecular sieve. It should be noted that there was a slightly more distorted over Cu-SSZ-13 considering its broader signal because the degree of distortion of the tetrahedral $\mathrm{Al}$ was in accordance with the signal width $[17,18]$. Apparently, the introduction of Ce led the zeolite body to relax and decreased this type of distortion since the signal had narrowed down instead of broadening. However, it was clearly shown that slight skeleton dealumination took place on Ce-modified Cu-SSZ-13 catalysts during the calcination process because of the weak signal intensities. This finding was not consistent with the result of XRD. In the ${ }^{29} \mathrm{Si}$ NMR spectra (Figure $4 \mathrm{~b}$ ), the dominant peak at around $115 \mathrm{ppm}$ was assigned to the presence of tetrahedral $\mathrm{Si}$ species $\left(\mathrm{Si}(\mathrm{OSi})_{4}\right)$ in the framework, and another weaker feature at $109 \mathrm{ppm}$ was attributed to tetrahedral $\mathrm{Si}$ with three Si and one Al neighbor $\left(\mathrm{Si}-(\mathrm{OSi})_{3}-(\mathrm{OAl})\right)$ [17-19]. As we know, dealumination would cause the intensity of the $109 \mathrm{ppm}$ signal to decrease [18]. However, it was worth pointing out that intensities for both signals decreased or increased at the same time after the introduction of Ce. Thus, this phenomenon was not a strong indication of the existence of dealumination.

\section{4. $H_{2}-T P R$ Measurements}

The $\mathrm{H}_{2}$-TPR profiles over the Cu-SSZ-13 and Ce-modified Cu-SSZ-13 catalysts were presented in Figure 5. Obviously, all the catalysts exhibited different reduction behaviors, indicating the presence of different $\mathrm{Cu}$ and Ce species in the catalysts. For Cu-SSZ-13, the original TPR curve from 170 to $670{ }^{\circ} \mathrm{C}$ could be accurately divided into four peaks after peak fitting process on the basis of the Gaussian deconvolution, and each peak corresponded with the reduction of one kind of $\mathrm{Cu}$ species. According to literature [20], the peak over 
Cu-SSZ-13 appearing at $256{ }^{\circ} \mathrm{C}$ was assigned to the reduction of isolated $\mathrm{Cu}^{2+}$ ions in the $\mathrm{CHA}$ cage. The peak around $368^{\circ} \mathrm{C}$, which was the strongest one in intensity among these $\mathrm{H}_{2}$ peaks, represented the reduction of $\mathrm{Cu}^{2+}$ ions on the D6R. This was consistent with the earlier report that the ion-exchange sites on the D6R were first saturated by $\mathrm{Cu}^{2+}$ ions and then coordinated to the $\mathrm{CHA}$ cage, and the former required a higher temperature compared to that on other sites because of its highly stable nature in the CHA-type zeolite structure [21]. The high-temperature peak around $406{ }^{\circ} \mathrm{C}$ could be attributed to the reduction of $\mathrm{Cu}^{+}$to $\mathrm{Cu}^{0}$. In addition, the peak located at about $539{ }^{\circ} \mathrm{C}$ corresponded to the reduction of highly stable $\mathrm{Cu}^{+}$ions to $\mathrm{Cu}^{0}[20,21]$. We observed, however, that $\mathrm{Ce} / \mathrm{Cu}-\mathrm{SSZ}$ 13 catalysts exhibited different reducibility properties that depended on the ion-exchange sequence of $\mathrm{Cu}$ and $\mathrm{Ce}$ species. It was noted that almost all the reduction temperatures of $(\mathrm{CeCu}) 12$ and $(\mathrm{CeCu}) 1 \mathrm{Cu} 2$ samples shifted to much lower values with respect to $\mathrm{Cu}-\mathrm{SSZ}-13$, while a slight difference in the peak temperature between the $\mathrm{Cu} 1(\mathrm{CeCu}) 2$ and $\mathrm{Cu}-\mathrm{SSZ}-13$ samples was in fact observed. From this result, we could first conclude that the stability of the zeolite structure of $\mathrm{Cu}-\mathrm{SSZ}-13$ and $\mathrm{Cu} 1(\mathrm{CeCu}) 2$ was better than that of $(\mathrm{CeCu}) 12$ and $(\mathrm{CeCu}) 1 \mathrm{Cu} 2$. Remarkably, with the introduction of Ce to the Cu-SSZ-13 catalysts, a clear increase in the amount of reduction of metal ion on D6R and CHA cage was observed. Also, there was quite a significant increase when computing the total $\mathrm{H}_{2}$ consumption (shown in Table 2), indicating that the location and coordination environment of copper ions might change, and cerium ions also participated in the reduction process. Besides, comparing the peak concentrations of the reduction of metal ion species could give information about the reducibility of the four samples (Table 2). We further investigated that the ion-exchange sequence of $\mathrm{Cu}$ and $\mathrm{Ce}$ species influenced the coordination between $\mathrm{Cu}$ and $\mathrm{Al}$ atoms of the zeolite framework. In particular, the fraction of first peak attributed to $[\mathrm{Cu}(\mathrm{OH})]^{+}$in CHA cage in $(\mathrm{CeCu}) 1 \mathrm{Cu} 2(10.5 \%)$ was significantly lower than that of Cu-SSZ-13 (21.8\%). On the other hand, as proposed by Usui and coworkers [5], the introduction of Ce in Cu-SSZ-13 should be located in the CHA cage because of the relatively large ionic radius of Ce (1.1 $\AA$ ). Therefore, it was reasonable to assume that a portion of Ce cations was introduced into CHA cages and replaced the unstable $\mathrm{Cu}^{2+}$ ions upon the ion exchange of SSZ-13 in cerium nitrate solutions. On the contrary, we noticed that Ce-modified samples contained higher fractions of more stable $\mathrm{Cu}^{2+}$ in D6R, the reduction peak of that, however, was shifted to a lower temperature in $(\mathrm{CeCu}) 12\left(347^{\circ} \mathrm{C}\right)$ and $(\mathrm{CeCu}) 1 \mathrm{Cu} 2\left(327^{\circ} \mathrm{C}\right)$ compared to $\sim 360^{\circ} \mathrm{C}$ for $\mathrm{Cu}-\mathrm{SSZ}-13$. Consequently, the ion-exchange sequence of $\mathrm{Cu}$ and $\mathrm{Ce}$ species influenced the reduction of the catalysts, and the improvement of redox properties over Ce-modified Cu-SSZ-13 samples would be beneficial for the low temperature catalytic reactivity [22]. This was in agreement with the results of the $\mathrm{NH}_{3}-\mathrm{SCR}$ performance.

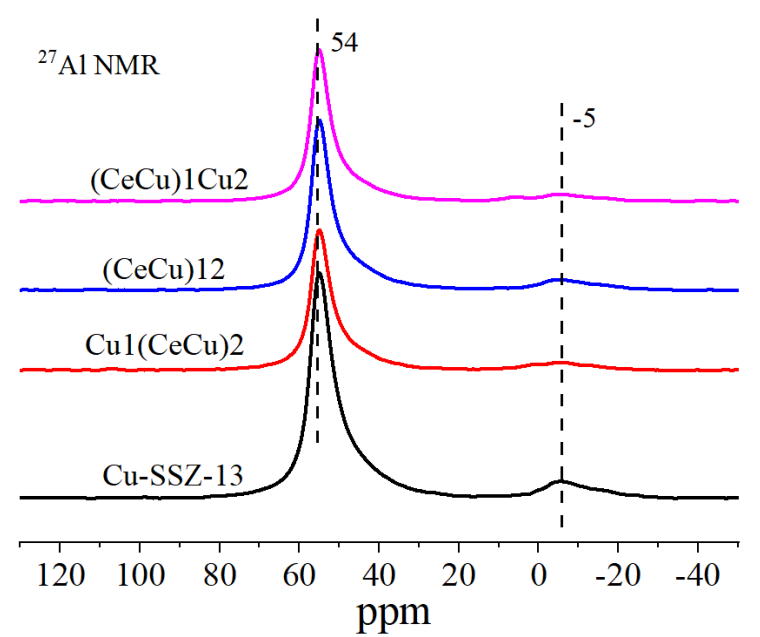

(a)

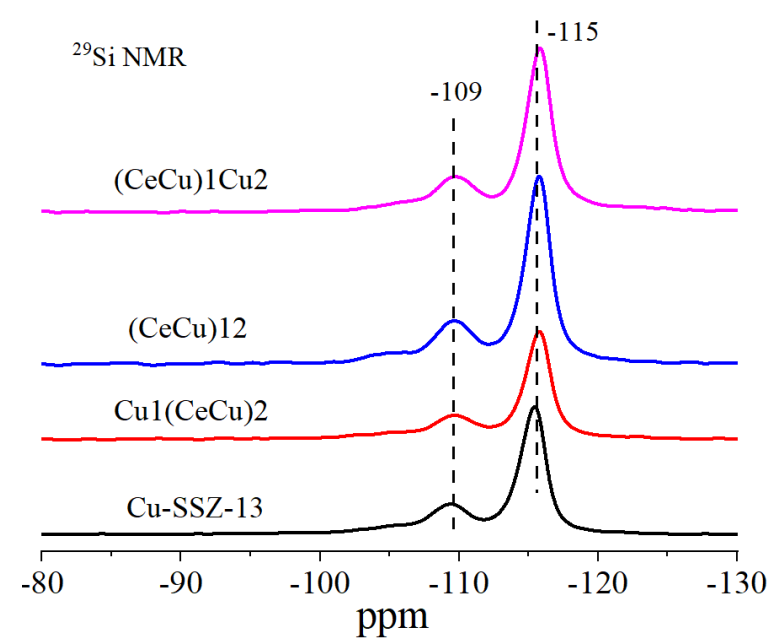

(b)

Figure 4. Solid state ${ }^{27} \mathrm{Al}(\mathbf{a})$ and ${ }^{29} \mathrm{Si}$ (b) MAS NMR spectra of Cu-SSZ-13 and Ce-modified Cu-SSZ-13 catalysts. 


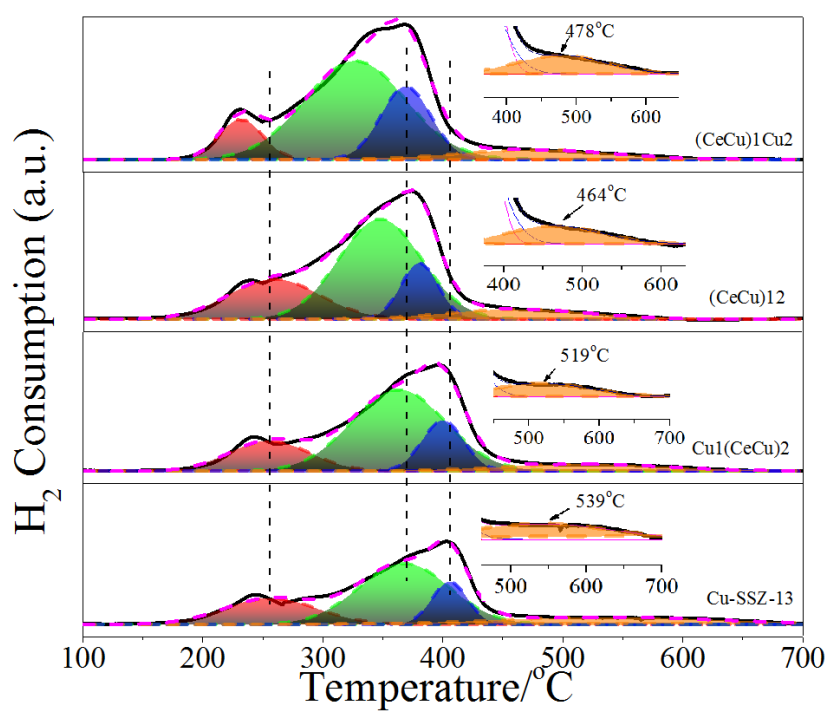

Figure 5. $\mathrm{H}_{2}$-TPR profiles of Cu-SSZ-13 and Ce-modified Cu-SSZ-13 catalysts.

Table 2. Quantitative analysis of the TPR and TPD profiles of Cu-SSZ-13 and Ce-modified Cu-SSZ-13 catalysts.

\begin{tabular}{|c|c|c|c|c|c|c|}
\hline \multirow{2}{*}{ Samples } & \multirow{2}{*}{$\begin{array}{c}\mathrm{H}_{2} \text { Total } \\
\text { Consumption } \\
\left(\mathrm{cm}^{3} / \mathrm{g}\right)\end{array}$} & \multirow{2}{*}{$\begin{array}{l}\text { Acidity } \\
\left(\mathrm{cm}^{3} / \mathrm{g}\right)\end{array}$} & \multicolumn{2}{|c|}{ Peak Concentration from $\mathrm{H}_{2}-\mathrm{TPR}(\%)^{a}$} & \multicolumn{2}{|c|}{$X^{b} / C u-S S Z-13$ from $\mathrm{NH}_{3}$-TPD (\%) } \\
\hline & & & Peak 1 & Peak 2 & Peak 2 & Peak 3 \\
\hline Cu-SSZ-13 & 44.9 & 32.7 & 21.8 & 49.7 & - & - \\
\hline $\mathrm{Cu} 1(\mathrm{CeCu}) 2$ & 51.0 & 35.5 & 18.2 & 57.3 & 5.9 & 3.1 \\
\hline$(\mathrm{CeCu}) 12$ & 62.8 & 39.1 & 23.7 & 53.9 & 15.2 & 2.6 \\
\hline$(\mathrm{CeCu}) 1 \mathrm{Cu} 2$ & 76.1 & 47.8 & 10.5 & 59.3 & 12.4 & 1.8 \\
\hline
\end{tabular}

${ }^{a}$ Peak 1 was the green peak, and peak 2 was the blue peak in Figure $5 .{ }^{b} \mathrm{X}$ represented $\mathrm{Cu} 1(\mathrm{CeCu}) 2,(\mathrm{CeCu}) 12$ or $(\mathrm{CeCu}) 1 \mathrm{Cu} 2 ;$ Peak 2 and peak 3 were the blue and magenta peak in Figure 6, respectively.

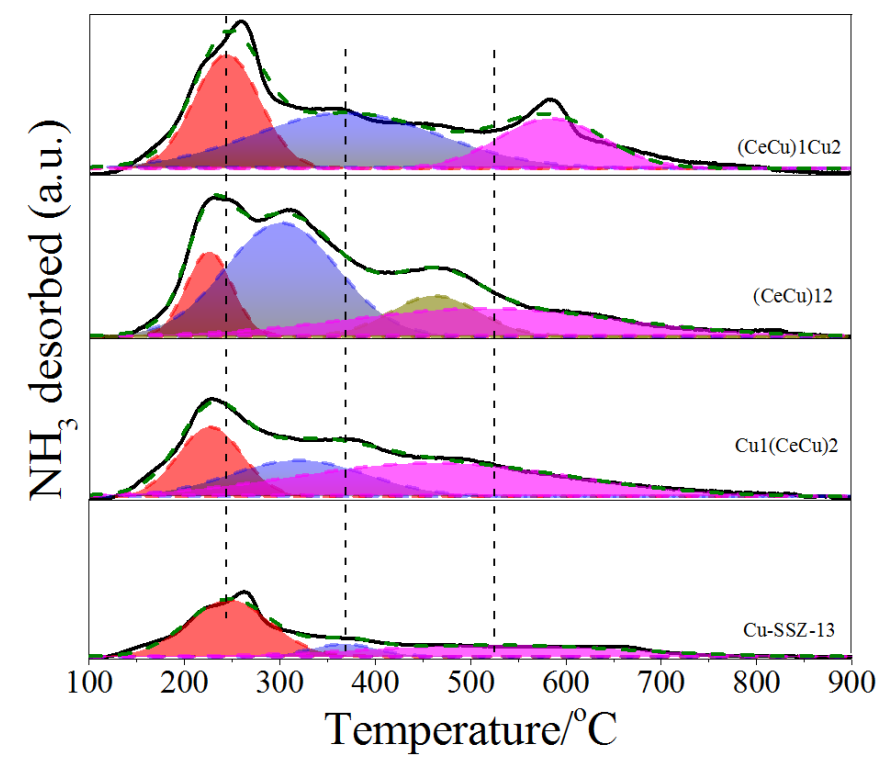

Figure 6. $\mathrm{NH}_{3}$-TPD profiles of Cu-SSZ-13 and Ce-modified Cu-SSZ-13 catalysts.

\section{5. $\mathrm{NH}_{3}-\mathrm{TPD}$ Measurements}

Through $\mathrm{NH}_{3}$-TPD measurements, it was possible not only to determine the acidity of the catalyst but also to titrate different acid sites present in zeolite catalysts. The TPD plots of the Cu-SSZ-13 and Ce-modified Cu-SSZ-13 catalysts were presented in Figure 6. The $\mathrm{Cu}-\mathrm{SSZ}-13$ was characterized by three $\mathrm{NH}_{3}$ peaks, and where the peak centered at about 
$246{ }^{\circ} \mathrm{C}$ probably corresponded to $\mathrm{NH}_{3}$ weakly adsorbed on extra-framework $\mathrm{Al}$ Lewis sites or loosely bound ammonia not removed during the purge step, and the $\mathrm{NH}_{3}$ adsorption peak at around $367^{\circ} \mathrm{C}$ represented acid sites in D6R, while the high-temperature $\left(528^{\circ} \mathrm{C}\right)$ peak could be related majorly to $\mathrm{NH}_{3}$ desorbed from acid sites in CHA cages $[7,21,23]$. When the catalysts were promoted with Ce ions, the effect of co-cations on the acidity of Cu-SSZ-13 was noteworthy, as an increase in the $\mathrm{NH}_{3}$ desorption amounts of all the Ce-modified samples was appreciable over the whole desorption temperature range. These results suggested that some new sites were created by Ce species. However, the effect of Ce on the overall $\mathrm{NH}_{3}$ storage capacity was quite different for the Cu-SSZ-13 with varied ionexchange sequence of $\mathrm{Cu}$ and $\mathrm{Ce}$ species. For instance, $\mathrm{Cu} 1(\mathrm{CeCu}) 2 / \mathrm{Cu}-\mathrm{SSZ}-13$ equaled 5.9 for the intermediate peak and 3.1 for the high temperature peak, while the ratios were 15.2, 2.6 and 12.4, 1.8 for $(\mathrm{CeCu}) 12 / \mathrm{Cu}-S S Z-13$ and $(\mathrm{CeCu}) 1 \mathrm{Cu} 2 / \mathrm{Cu}-\mathrm{SSZ}-13$ respectively, which was clearly seen in Table 2. Obviously, there was a much larger growth trend of acid sites in $\mathrm{CHA}$ cage over $\mathrm{Cu} 1(\mathrm{CeCu}) 2$ catalyst, while the $(\mathrm{CeCu}) 12$ and $(\mathrm{CeCu}) 1 \mathrm{Cu} 2$ samples maintained higher $\mathrm{NH}_{3}$ storage capacity in D6R. These different contributions to the $\mathrm{NH}_{3}$ storage could explain why Ce-modified Cu-SSZ-13 catalysts had different SCR performance when ion-exchange sequence of $\mathrm{Cu}$ and $\mathrm{Ce}$ species varied. Notice that $(\mathrm{CeCu}) 12$ also showed a weak desorption peak at around $463{ }^{\circ} \mathrm{C}$, which might be attributed to the medium-strength acid sites. According to the early report by Wang et al. [7], the ion exchange of Ce could replace a small fraction of unstable $[\mathrm{Cu}(\mathrm{OH})]^{+}$ions in $\mathrm{CHA}$ cages. Meanwhile, as reported by Gao et al. [24], the $[\mathrm{Cu}(\mathrm{OH})]^{+}$could convert to "naked" $\mathrm{Cu}^{2+}$ ions and move to the sites in windows of $6 \mathrm{MR}$ during the dehydration procedure. Taken together with TPR results above, it was reasonable to assume that the extra desorption peak of $(\mathrm{CeCu}) 12$ mainly resulted from the movement of $[\mathrm{Cu}(\mathrm{OH})]^{+}$ions. As already shown in literature by Paolucci et al. [25], $[\mathrm{Cu}(\mathrm{OH})]^{+}$and $\mathrm{Cu}^{2+}$ differed in their $\mathrm{NH}_{3}$ coordination behavior: $[\mathrm{Cu}(\mathrm{OH})]^{+}$could be able to coordinate and store $3 \mathrm{NH}_{3}$, while $\mathrm{Cu}^{2+}$ could store up to $4 \mathrm{NH}_{3}$. It was understandable that the sample containing replacement of $\mathrm{Ce}$ and movement of $\mathrm{Cu}$ in the preparation process could likely form more acidic sites and thus improve the storage capacity of ammonia.

\section{Materials and Methods}

\subsection{Catalyst Preparation}

The parent H-SSZ-13 with the mole ratio of $\mathrm{SiO}_{2} / \mathrm{Al}_{2} \mathrm{O}_{3}=22$ was directly provided by Zeolite Company. The initial H-SSZ-13 powder was ion exchanged twice in $0.05 \mathrm{M}$ $\mathrm{Cu}\left(\mathrm{CH}_{3} \mathrm{COO}\right)_{2}$ solution at ambient temperature for $6 \mathrm{~h}$, and the ratio of solid to solution was 1:40. After that, the powder was filtered, washed, and calcined at $550{ }^{\circ} \mathrm{C}$ for $6 \mathrm{~h}$. Finally, Cu-SSZ-13 catalyst was obtained.

At the same time, the Ce-modified Cu-SSZ-13 catalysts were prepared using the same ion-exchange procedure, and the influence of $\mathrm{Ce}$ in the catalyst was controlled by the different exchange sequences with $\mathrm{Cu}$. For the $\mathrm{Cu} 1(\mathrm{CeCu}) 2$ sample, the initial H-SSZ-13 powder was firstly ion exchanged in $0.05 \mathrm{M} \mathrm{Cu}\left(\mathrm{CH}_{3} \mathrm{COO}\right)_{2}$ solution at ambient temperature for $6 \mathrm{~h}$. After filtered, washed, and calcined, the power was added into $0.05 \mathrm{M} \mathrm{Cu}\left(\mathrm{CH}_{3} \mathrm{COO}\right)_{2}$ and $0.00625 \mathrm{M} \mathrm{Ce}\left(\mathrm{NO}_{3}\right)_{3} \cdot 6 \mathrm{H}_{2} \mathrm{O}$ solution with vigorous stirring for $6 \mathrm{~h}$. Then the powder was filtered, washed, and calcined at $550{ }^{\circ} \mathrm{C}$ for $6 \mathrm{~h}$. The $(\mathrm{CeCu}) 12$ was produced using ion exchange (twice) of H-SSZ-13 with an aqueous solution of $0.05 \mathrm{M} \mathrm{Cu}\left(\mathrm{CH}_{3} \mathrm{COO}\right)_{2}$ and $0.00625 \mathrm{M} \mathrm{Ce}\left(\mathrm{NO}_{3}\right)_{3} \cdot 6 \mathrm{H}_{2} \mathrm{O}$ solution at $25^{\circ} \mathrm{C}$ for $6 \mathrm{~h}$. Then, the zeolite slurries were filtered, washed with deionized water and calcined at $550{ }^{\circ} \mathrm{C}$ for $6 \mathrm{~h}$. For the $(\mathrm{CeCu}) 1 \mathrm{Cu} 2$ sample, H-SSZ-13 was exchanged with $0.05 \mathrm{M} \mathrm{Cu}\left(\mathrm{CH}_{3} \mathrm{COO}\right)_{2}$ and $\mathrm{Ce}\left(\mathrm{NO}_{3}\right)_{3} \cdot 6 \mathrm{H}_{2} \mathrm{O}$ solution firstly and then $0.05 \mathrm{M} \mathrm{Cu}\left(\mathrm{CH}_{3} \mathrm{COO}\right)_{2}$ solution at $25^{\circ} \mathrm{C}$ for $6 \mathrm{~h}$. After that, the powder was filtered, washed, and calcined at $550{ }^{\circ} \mathrm{C}$ for $6 \mathrm{~h}$.

\subsection{Catalyst Characterization}

XRD was conducted on a Bruker D8 advance (Bruker, Karlsruhe, Baden-Wurttemberg, Germany); the diffraction angle ranged from 5 to $90^{\circ}$ using $\mathrm{Cu} \mathrm{K} \alpha$ radiation at $40 \mathrm{~mA}$ 
and $40 \mathrm{kV} . \mathrm{N}_{2}$ adsorption and desorption was conducted on a Micromeritics ASAP 2020 physical adsorption instrument (Micromeritics, Norcross, GA, USA). ${ }^{29}$ Si and ${ }^{27}$ Al NMR spectra were carried out on Agilent 600M (Agilent, Palo Alto, CA, USA) utilizing a 4 mm MAS probe. $\mathrm{H}_{2}$-TPR and $\mathrm{NH}_{3}$-TPD were performed on an AutoChemII2920 chemisorption analyzer (Micromeritics, Norcross, GA, USA), and the catalyst sample was pretreated under $\mathrm{N}_{2}$ at $300{ }^{\circ} \mathrm{C}$ for $1 \mathrm{~h}$ and then cooled down to $50{ }^{\circ} \mathrm{C}$. After that, the catalyst was heated to the required temperature at $10{ }^{\circ} \mathrm{C} / \mathrm{min}$ in a $5 \% \mathrm{H}_{2} / \mathrm{Ar}$ or $6000 \mathrm{ppm} \mathrm{NH}_{3} / \mathrm{Ar}$ at a flow rate of $50 \mathrm{~mL} / \mathrm{min}$.

\subsection{Activity Evaluation}

De- $\mathrm{NO}_{x}$ tests of catalysts were conducted on a fixed-bed quartz reactor. The gas composition was composed of $200 \mathrm{ppm} \mathrm{NH}_{3}, 200 \mathrm{ppm} \mathrm{NO}, 5 \% \mathrm{H}_{2} \mathrm{O}, 10 \% \mathrm{O}_{2}, 50 \mathrm{ppm} \mathrm{C}_{3} \mathrm{H}_{6}$, $4.5 \% \mathrm{CO}_{2}, 200 \mathrm{ppm} \mathrm{CO}$, and balance $\mathrm{N}_{2}$. The total gas flow rate was $300 \mathrm{~mL} \cdot \mathrm{min}^{-1}$ and the gas hourly space velocity was $250,000 \mathrm{~h}^{-1}$. The concentration of $\mathrm{NO}_{x}$ was monitored by an online flue gas analyzer. The $\mathrm{NO}_{x}$ conversion was calculated as $\mathrm{NOx}$ conversion $=$ $\frac{[\mathrm{NOx}]_{\text {inlet }}-[\mathrm{NOx}]_{\text {outlet }}}{[\mathrm{NOx}]_{\text {inlet }}} \times 100 \%$, where $\mathrm{NO}_{x}=\mathrm{NO}+\mathrm{NO}_{2}[8]$.

\section{Conclusions}

Comparing the Cu-SSZ-13 and Ce-modified Cu-SSZ-13 catalysts synthesized via aqueous ion-exchange, and effects of $\mathrm{Ce}$ and $\mathrm{Cu}$ ion-exchange sequences on $\mathrm{NO}_{x}$ conversion in $\mathrm{NH}_{3}$-SCR reaction and the related physical and chemical properties were explored and analyzed in detail. The XRD as well as ${ }^{27} \mathrm{Al}$ and ${ }^{29} \mathrm{Si}$ NMR results indicated that the ionexchange sequence of $\mathrm{Cu}$ and $\mathrm{Ce}$ species influenced the crystallinity of the zeolites and the coordination of Al. $\mathrm{H}_{2}$-TPR demonstrated that the location and coordination environment of copper ions might change after introduction of a small amount $\mathrm{Ce}$, and $\mathrm{Ce}$ ions also participated in the reduction process. Moreover, the improvement of redox properties over Ce-modified Cu-SSZ-13 samples would be beneficial for the low temperature catalytic reactivity. $\mathrm{NH}_{3}$-TPD analysis confirmed that Ce-modified Cu-SSZ-13 catalysts with varied ion-exchange sequence of $\mathrm{Cu}$ and $\mathrm{Ce}$ species had different $\mathrm{NH}_{3}$ storage performance, and the sample containing replacement of $\mathrm{Ce}$ and movement of $\mathrm{Cu}$ in the preparation process could likely form more acidic sites and thus improve the storage capacity of ammonia. The $\mathrm{Cu} 1(\mathrm{CeCu}) 2$ catalyst exchanged $\mathrm{Cu}$ firstly and then $\mathrm{Ce}$ and $\mathrm{Cu}$ at the same time, demonstrating excellent catalytic activity, and over $90 \% \mathrm{NO}_{x}$ conversion of fresh catalyst was obtained across the temperature range of $200-500^{\circ} \mathrm{C}$. Therefore, the cooperation of strong redox abilities and $\mathrm{NH}_{3}$ storage capacity led to the increase of active adsorbed species adsorption and resulted in the better activity of $\mathrm{Cu} 1(\mathrm{CeCu}) 2$.

Author Contributions: Conceptualization, Y.W. (Yan Wang); Investigation, Y.W. (Yan Wang), Z.D., N.K., R.F., C.Z., Y.W. (Yu Wang), R.W. and X.G.; Data Curation, Y.W. (Yan Wang); Writing-Review \& Editing, Y.W. (Yan Wang); Supervision, Z.L.; Project Administration, Z.L. All authors have read and agreed to the published version of the manuscript.

Funding: This research received no external funding.

Data Availability Statement: Data is contained within the article.

Conflicts of Interest: The authors declare no conflict of interest.

\section{References}

1. Shan, Y.L.; Du, J.P.; Zhang, Y.; Shan, W.P.; Shi, X.Y.; Yu, Y.B.; Zhang, R.D.; Meng, X.J.; Xiao, F.S.; He, H. Selective catalytic reduction of $\mathrm{NO}_{x}$ with $\mathrm{NH}_{3}$ : Opportunities and challenges of Cu-based small-pore zeolites. Natl. Sci. Rev. 2021, 8, 1-10.

2. Clark, A.H.; Nuguid, R.J.G.; Steiger, P.; Marberger, A.; Petrov, A.W.; Ferri, D.; Nachtegaal, M.; Kröcher, O. Selective catalytic reduction of $\mathrm{NO}$ with $\mathrm{NH}_{3}$ on Cu-SSZ-13: Deciphering the low and high-temperature rate-limiting steps by transient XAS experiments. Chem CatChem 2020, 12, 1429-1435. [CrossRef]

3. Chen, M.Y.; Sun, Q.M.; Yang, X.G.; Yu, J.H. A dual-template method for the synthesis of bimetallic CuNi/SSZ-13 zeolite catalysts for $\mathrm{NH}_{3}$-SCR reaction. Inorg. Chem. Commun. 2019, 105, 203-207. [CrossRef] 
4. Bendrich, M.; Scheuer, A.; Hayes, R.E.; Votsmeier, M. Increased SCR performance of Cu-CHA due to ammonium nitrate buffer: Experiments with oscillating $\mathrm{NO} / \mathrm{NO}_{2}$ ratios and application to real driving cycles. Appl. Catal. B Environ. 2020, 270, 118763-118771. [CrossRef]

5. Usui, T.; Liu, Z.D.; Ibe, S.; Zhu, J.; Anand, C.; Igarashi, H.; Onaya, N.; Sasaki, Y.; Shiramata, Y.; Kusamoto, T.; et al. Improve the hydrothermal stability of Cu-SSZ-13 zeolite catalyst by loading a small amount of Ce. ACS Catal. 2018, 8, 9165-9173. [CrossRef]

6. Zhao, Z.C.; Yu, R.; Shi, C.A.; Gies, H.; Xiao, F.S.; Vos, D.D.; Yokoi, T.; Bao, X.H.; Kolb, U.; McGuire, R.; et al. Rare-earth ion exchanged Cu-SSZ-13 zeolite from organotemplate-free synthesis with enhanced hydrothermal stability in $\mathrm{NH}_{3}-\mathrm{SCR}$ of $\mathrm{NO}_{x}$. Catal. Sci. Technol. 2019, 9, 241-251. [CrossRef]

7. Wang, Y.J.; Shi, X.Y.; Shan, Y.L.; Du, J.P.; Liu, K.; He, H. Hydrothermal stability enhancement of Al-Rich Cu-SSZ-13 for NH 3 selective catalytic reduction reaction by ion eExchange with cerium and samarium. Ind. Eng. Chem. Res. 2020, 59, 6416-6423. [CrossRef]

8. Fan, J.; Ning, P.; Wang, Y.C.; Song, Z.X.; Liu, X.; Wang, H.M.; Wang, J.; Wang, L.Y.; Zhang, Q.L. Significant promoting effect of Ce or La on the hydrothermal stability of Cu-SAPO-34 catalyst for $\mathrm{NH}_{3}$-SCR reaction. Chem. Eng. J. 2019, 369, 908-919. [CrossRef]

9. Wang, Y.; Li, Z.Q.; Fan, R.R.; Guo, X.; Zhang, C.; Wang, Y.; Ding, Z.Y.; Wang, R.; Liu, W. Deactivation and regeneration for the $\mathrm{SO}_{2}$-poisoning of a Cu-SSZ-13 catalyst in the $\mathrm{NH}_{3}$-SCR reaction. Catalysts 2019, 9, 797. [CrossRef]

10. Liang, J.; Mi, Y.; Song, G.; Peng, H.G.; Li, Y.L.; Yan, R.; Liu, W.M.; Wang, Z.; Wu, P.; Liu, F.D. Environmental benign synthesis of Nano-SSZ-13 via FAU transcrystallization: Enhanced $\mathrm{NH}_{3}$-SCR performance on Cu-SSZ-13 with nanosize effect. J. Hazard. Mater. 2020, 398, 122986-122998. [CrossRef]

11. He, D.D.; Wang, Z.H.; Deng, D.; Deng, S.J.; He, H.; Liu, L.C. Synthesis of Cu-SSZ-13 catalyst by using different silica sources for NO-SCR by $\mathrm{NH}_{3}$. Mol. Catal. 2020, 484, 110738-110747. [CrossRef]

12. Wang, Y.; Nishitoba, T.; Wang, Y.N.; Meng, X.J.; Xiao, F.S.; Zhang, W.P.; Marler, B.; Gies, H.; Vos, D.D.; Kolb, U.; et al. Cu-exchanged CHA-Type zeolite from organic template-free synthesis: An effective catalyst for $\mathrm{NH}_{3}-\mathrm{SCR}$. Ind. Eng. Chem. Res. 2020, 59, 7375-7382. [CrossRef]

13. Su, W.K.; Li, Z.G.; Peng, Y.; Li, J.H. Correlation of the changes in the framework and active Cu sites for typical Cu/CHA zeolites (SSZ-13 and SAPO-34) during hydrothermal aging. Phys. Chem. Chem. Phys. 2015, 17, 29142-29149. [CrossRef] [PubMed]

14. Ma, L.; Cheng, Y.S.; Cavataio, G.; McCabe, R.W.; Fu, L.X.; Li, J.H. Characterization of commercial Cu-SSZ-13 and Cu-SAPO-34 catalysts with hydrothermal treatment for $\mathrm{NH}_{3}-\mathrm{SCR}$ of $\mathrm{NO}_{x}$ in diesel exhaust. Chem. Eng. J. 2013, 225, 323-330. [CrossRef]

15. Jiang, H.; Guan, B.; Lin, H.; Huang, Z. Cu/SSZ-13 zeolites prepared by in situ hydrothermal synthesis method as $\mathrm{NH}_{3}-\mathrm{SCR}$ catalysts: Influence of the $\mathrm{Si} / \mathrm{Al}$ ratio on the activity and hydrothermal properties. Fuel 2019, 255, 15587-115604. [CrossRef]

16. Cui, Y.R.; Wang, Y.L.; Walter, E.D.; Szanyi, J.; Wang, Y.; Gao, F. Influences of $\mathrm{Na}^{+}$co-cation on the structure and performance of $\mathrm{Cu} / \mathrm{SSZ}-13$ selective catalytic reduction catalysts. Catal. Today 2020, 339, 233-240. [CrossRef]

17. Wang, J.C.; Peng, Z.L.; Qiao, H.; Yu, H.F.; Hu, Y.F.; Chang, L.P.; Bao, W.R. Cerium-stabilized Cu-SSZ-13 catalyst for the catalytic removal of $\mathrm{NO}_{x}$ by $\mathrm{NH}_{3}$. Ind. Eng. Chem. Res. 2016, 55, 1174-1182. [CrossRef]

18. Luo, J.Y.; Gao, F.; Kamasamudram, K.; Currier, N.; Peden, C.H.F.; Yezerets, A. New insights into Cu/SSZ-13 SCR catalyst acidity. Part I: Nature of acidic sites probed by $\mathrm{NH}_{3}$ titration. J. Catal. 2017, 348, 291-299. [CrossRef]

19. Zhang, T.; Qiu, F.; Li, J.H. Design and synthesis of core-shell structured meso-Cu-SSZ-13@mesoporous aluminosilicate catalyst for SCR of $\mathrm{NO}_{x}$ with $\mathrm{NH}_{3}$ : Enhancement of activity, hydrothermal stability and propene poisoning resistance. Appl. Catal. B Environ. 2016, 195, 48-58. [CrossRef]

20. Kim, Y.J.; Lee, J.K.; Min, K.M.; Hong, S.B.; Nam, I.S.; Cho, B.K. Hydrothermal stability of CuSSZ13 for reducing NOx by NH 3 . J. Catal. 2014, 311, 447-457. [CrossRef]

21. Villamaina, R.; Liu, S.J.; Nova, I.; Tronconi, E.; Ruggeri, M.P.; Collier, J.; York, A.; Thompsett, D. Speciation of Cu cations in $\mathrm{Cu}-\mathrm{CHA}$ catalysts for $\mathrm{NH}_{3}$-SCR: Effects of $\mathrm{SiO}_{2} / \mathrm{AlO}_{3}$ ratio and $\mathrm{Cu}$-loading investigated by transient response methods. ACS Catal. 2019, 9, 8916-8927. [CrossRef]

22. Shan, W.; Geng, Y.; Chen, X.; Huang, N.; Liu, F.; Yang, S. A highly efficient CeWOx catalyst for the selective catalytic reduction of $\mathrm{NO}_{x}$ with $\mathrm{NH}_{3}$. Catal. Sci. Technol. 2016, 6, 1195-1200. [CrossRef]

23. Leistner, K.; Xie, K.P.; Kumar, A.; Kamasamudram, K.; Olsson, L. Ammonia Desorption Peaks Can Be Assigned to Different Copper Sites in Cu/SSZ-13. Catal. Lett. 2017, 147, 1882-1890. [CrossRef]

24. Gao, F.; Washton, N.M.; Wang, Y.; Kollar, M.; Szanyi, J.; Peden, C.H.F. Effects of Si / Al ratio on Cu/SSZ-13 NH $3-S C R$ catalysts: Implications for the active $\mathrm{Cu}$ species and the roles of Brønsted acidity. J. Catal. 2015, 331, 25-38. [CrossRef]

25. Paolucci, C.; Parekh, A.A.; Khurana, I.; Di Iorio, J.R.; Li, H.; Albarracin Caballero, J.D.; Shih, A.J.; Anggara, T.; Delgass, W.N.; Miller, J.T.; et al. Catalysis in a cage: Condition-dependent speciation and dynamics of exchanged Cu cations in SSZ-13 zeolites. J. Am. Chem. Soc. 2016, 138, 6028-6048. [CrossRef] [PubMed] 